\title{
Non-Exhaustible Solar-Power Based Insecticide or Bio-fertilizer Sprayer for Use in Agronomics (With Bluetooth Enabled Control)
}

\author{
B Dodda Basavana Goud*, K Raghavendra Prasad**, Shambulingana \\ Gouda***, Geetha H Y**** \\ *, **, ***(Department of Electrical \& Electronics Engineering, RYMEC, Ballari, Karnataka, India) \\ **** (Department of Electronics \& Communication Engineering, BITM, Ballari, Karnataka, India)
}

\begin{abstract}
Agronomics is a profession of many related sequential and sometimes concurrent tedious processes and methodologies. The Primary process among many is the spraying of insecticides, pesticides, liquefied fertilizers in the agricultural farmlands. The typical rice growing land requires extensive spraying during its growing stages. The manual methods to spray the insecticides or fertilizers are: a person fixing a sprayer to a container and manually actuating a lever to generate pressure and pumping the contents through a tube or a mobile vehicle carrying an inbuilt compressor and sprayer unit which has to be manually driven by a human operator. These conventional methods are more fuel consuming and are also susceptible to human errors causing more uneven spraying and causes large wastage of the costly insecticides. . Another big drawback in human operated systems is that the operator is more exposed to the harmful ingredients of the toxic insecticides during spraying. Long term exposure in the entire season will extremely harm the operator and as well as the surrounding people and animal's health as bullocks are the laboring animals in the farmlands at larger areas of farmlands in south-Asia even now. This is a small effort which can be observed as an alternate to these manual methods. The proposed Automatic sprayer system is a three wheeled vehicle which sprays insecticide in any given farmland especially the rice growing south Asia zone where human involvement is to the large extent. The vehicle is powered by using solar powered battery which brings down the running cost. The control of the vehicle is achieved using an inbuilt microcontroller unit which is programmed so as to respond to the wireless device.
\end{abstract}

Keywords: agronomics, rice farmlands, Automatic sprayer, insecticides.

\section{INTRODUCTION}

Agronomics refers to the oldest profession such as agriculture and comprises of many tedious processes and practices, one among them is spraying of insecticides in the farming land. The sprayers are mechanical devices that are especially designed to spray liquids fastly quickly and easily. These come in a number of different varieties. In this small project it is undertook solar operated mechanical sprayers. A sprayer of this type is a great way to use naturally available inexhaustible sun energy. Thus the solar dependant automatic insecticide sprayer is very much cost effective solution at the locations where spraying is difficult, dangerous and probably a costly process that includes more wastage. This automatic solar based pesticide sprayer system uses solar energy as source. Solar energy is first used to charge a storage battery. The solar energy stored in the battery is employed to operate motor which functions as pump. In this project we are proposing to make a prototype model for farmers and cultivators for whom spraying of insecticides is harmful and hazardous along with uneven spraying leading to wastage and making the agronomics more costly[1-6].

\section{LITERATURE REVIEW}

Types of Sprayers Presently in use are enlisted as below:

\subsection{Rucksack/knapsack Sprayer}

One type of rucksack or backpack sprayer is a compressed air sprayer with a harness that allows it to be carried on the operator's back depicted in fig.1. Another type of backpack sprayer has a hand-operated hydraulic pump that forces liquid pesticide through a hose and one or more nozzles. The pump is usually activated by moving a lever. A mechanical agitator plate may be attached to the pump plunger. Some of these sprayers can generate pressures of 100 pounds per square inch (psi) or more. Capacity of both these types of backpack sprayers is usually 5 gallons or less. Hydraulic sprayers consist of a tank, a pump, a lance (for single nozzles) or boom, and a nozzle (or multiple nozzles). Sprayers convert a pesticide formulation, often containing a mixture of water (or another liquid chemical carrier, such as fertilizer) 
and chemical, into droplets, which can be large raintype drops or tiny almost-invisible particles. This conversion is accomplished by forcing the spray mixture through a spray nozzle under pressure[7].

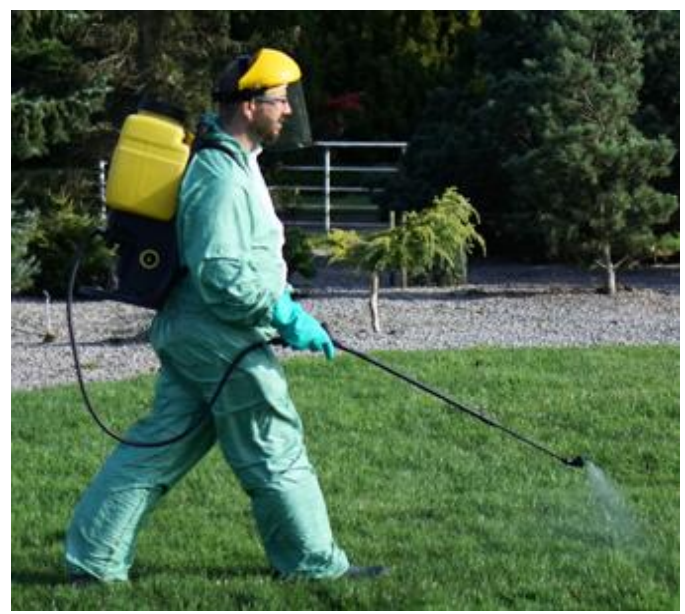

Fig.1: Knapsack Sprayer

\subsection{Hand Compression Sprayer}

Hand compression sprayers are either pressure retaining or non pressure retaining type. The pressure retaining type has an advantage that once air charged it may last for more than seven days, but requires sturdy tank and high pressure, therefore these are not in common use. Non-pressure retaining type is the most commonly used hand compression sprayer. Like other sprayers, it consists of an airtight, metallic tank, air pump, lance fitted with trigger type or shut off valve, gooseneck bend a pair of shoulder mounted straps and nozzle shown in fig.2[9].

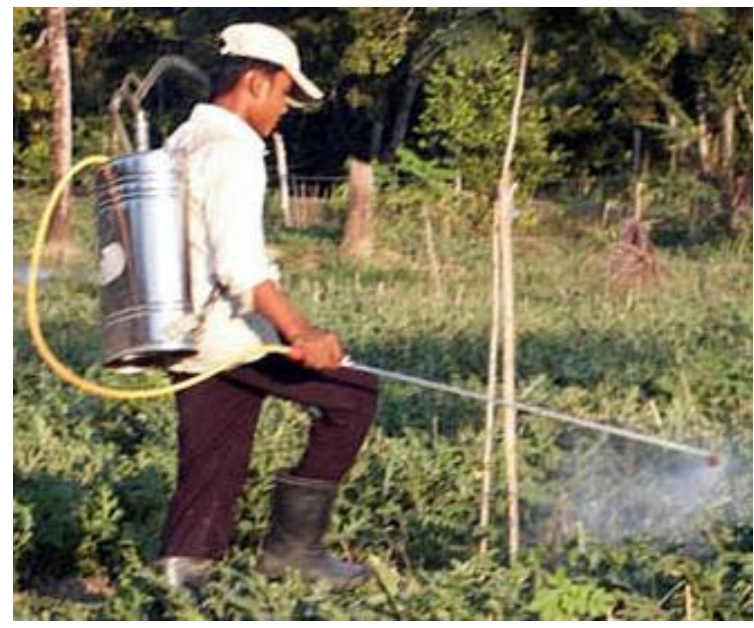

Fig.2: Hand Compression Spray

It is to carry it over the back. All the parts are made from brass alloy and the tank is modeled to withstand high pressure up to the order of 18 $\mathrm{kg} / \mathrm{cm} 2$. For operation, the tank is filled to three fourth of its capacity and pressurized by hand plunger pump, which remain inside the tank or from a compressor. The pressure inside the tank is usually maintained at $3-4 \mathrm{~kg} / \mathrm{cm} 2$. The operator mounts the sprayer on his back securing it by shoulder straps and operates the trigger valve, which enables the spray liquid to flow through lance and nozzle. The lance is directed towards the target. A single person can operate the sprayer. For maintaining proper atomization of the spray liquid, the tank requires frequent pressurization decreases with decrease in pressure.

\subsection{Engine Operated Sprayer}

The fig. 3 shows the Engine operated Sprayer. The power sprayer consists of an integrated or external spray tank; a high pressure piston pump usually powered by a petrol engine a pressure regulating valve and a hose of up to $50 \mathrm{~m}$ of length. Spray tanks are too big to be carried as a knapsack. The power sprayer is produced in a number of versions. Most simple and common is an engine driven pump mounted on a frame without wheels, a 2001 drum and hose and lance. Flow regulation is to be done via a pressure regulating valve and/or by restrictors (basic power sprayer) and the size of the nozzle. At the other end of sprayers mounted on wheels, equipped with pressure regulators. Technically, the power sprayer has a lot in common with the motorized knapsack-sprayer. The unit is generally set for high volume spraying, transporting the droplets with high pressure. Hallow cone nozzles are the preferred type of nozzles[4,8].

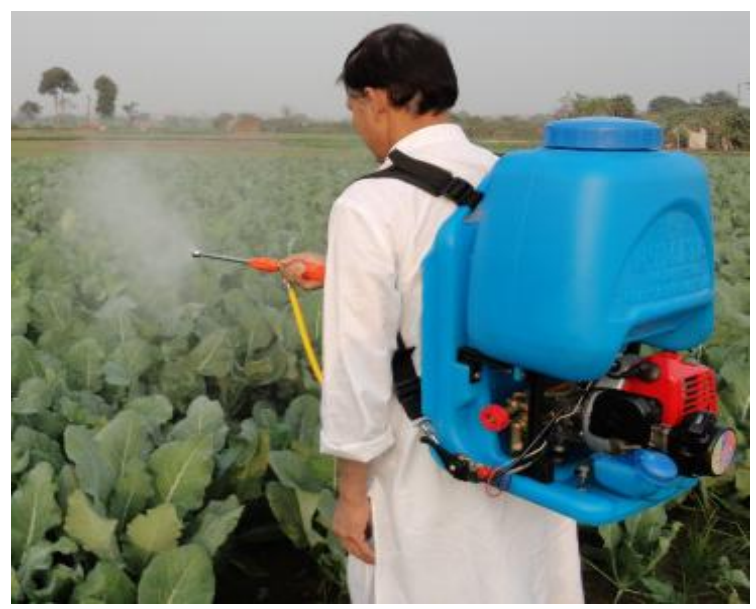

Fig.3: Engine operated sprayer

\subsection{Power Tiller Mounted Orchard Sprayer:}

It consists of an HTP pump, trailed type main chassis with transport wheels, chemical tank with hydraulic agitation system, cut off device and boom equipped with turbo nozzles. It is fitted with turbo nozzles with operating pressure of 9-18 $\mathrm{kg} / \mathrm{cm} 2$. It generates droplets of 100-150 micron sizes. Depending upon the plant size and their row 
spacing, the orientation of booms can be adjusted [3]. The spray booms are mounted behind the operator shown in fig. 4.

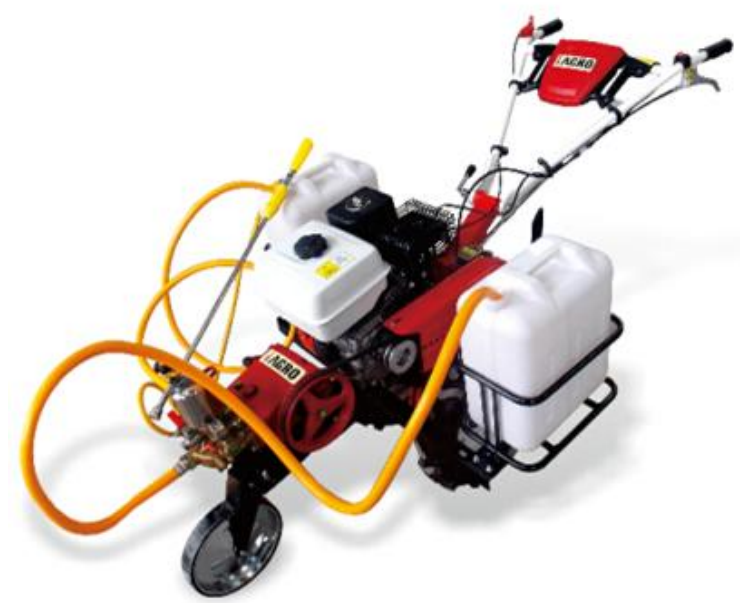

Fig. 4: Power Tiller sprayer

\section{PREVIOUS WORKS IN THIS FIELD}

Autonomous service robots for orchards and vineyards: $3 \mathrm{~d}$ simulation environment of multi sensor based navigation and applications Linz, A. Ruckelshausen and E. Wunder (2014),[1] - The authors are working in the fields of unmanned or remote controlled autonomous field robots, navigation, image-based sensors fusion as well as agricultural applications. Within an interdisciplinary research group these technologies are transferred to robot applications in vineyards and orchards. The goal is the availability of an autonomous service robot, whereas first applications are site-specific plant protection (e.g. precise spraying), mulching and picking up fruit boxes. A first version of the robot with electrical drives and precise sprayers has already been developed. The applications, however, show a large range of field conditions which have to be considered for the vehicle application design. Thus the authors have developed a 3D simulation environment which allows the virtual test of the robot platform prior to its application.

\section{EXISTING SYSTEM}

The solar powered insecticide sprayer that is in general has to be sprayed manually. In the commonly available ones, the user needs to exert a lot of effort to push the lever up and down to create the pressure to spray. Sometimes when the pressure becomes uneven, the nozzle gets blocked and the farmer has to spend time to rectify it. Also the pesticide is harmful and it also affects the farmers and cultivators due to their presence while spraying in the vineyard. As shown in the fig. 5 the farmer sprays pesticide manually[1-3,5,6].

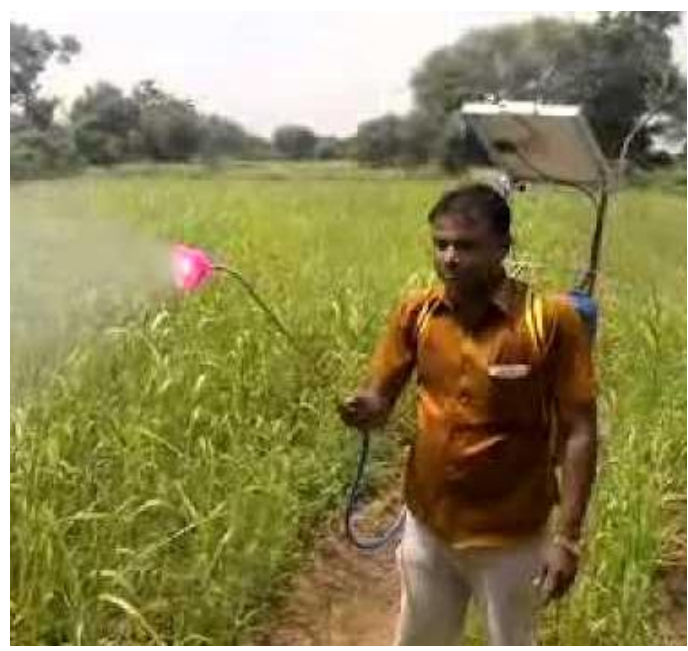

Fig 5: Manual Solar Powered Sprayer

\section{Proposed System}

The proposed system as an Automatic insecticide Sprayer which is expected to achieve better results compared to the earlier methods without any human support. This would be an automatic mechanical model that would work automatically that is driven by solar energy and reduce monotonous works and also protect the farmers and cultivators from harmful pesticides and chemicals apart from the uneven spraying ill effects.

\section{METHODOLOGY}

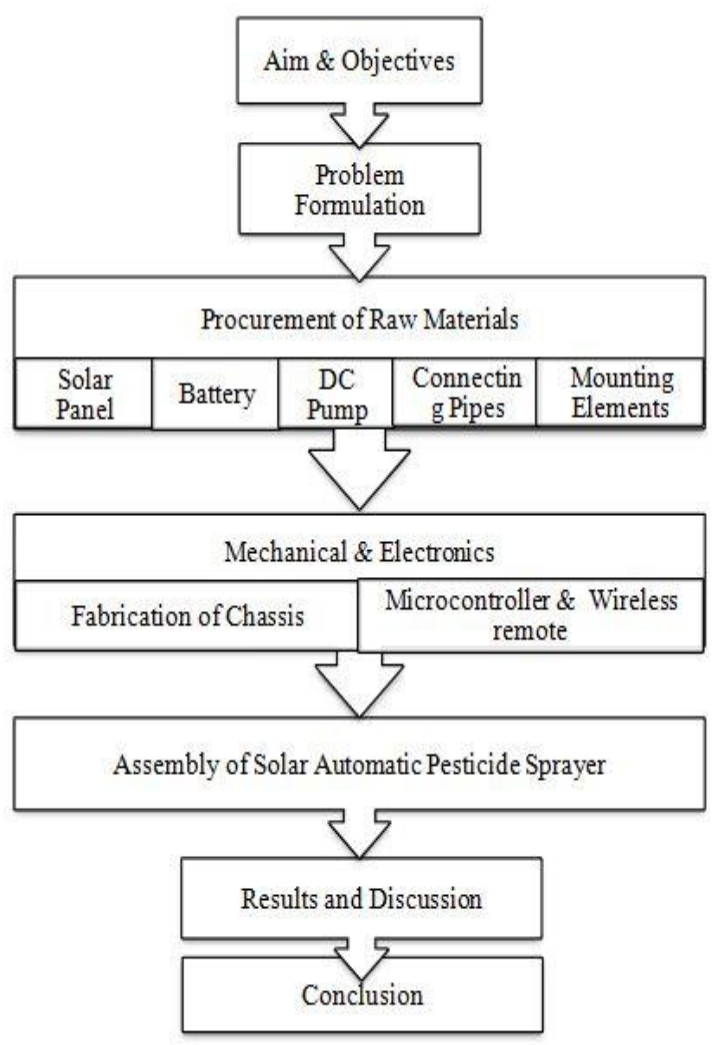

Fig.6: Flowchart 
The flowchart explains the methodology of the paper in fig. 6. The foremost and preliminary step involved is the selection of the project. After weighing in various factors like feasibility, cost, usefulness and challenges involved, we settled with this project. This was done after extensive discussions within our working team. After selection of proposed project we then selected the various general elements required for the project. This involved sourcing a welder and getting a quote on the steel pipes used.

We next designed the chassis of the sprayer part of the device. We based this on a guided vehicle structure and made the necessary modifications. The electrical components were selected to best suit the project requirements. The circuit diagram was used as a basis for selection of components. The next step involved is two steps that are carried out almost simultaneously - the fabrication of the model according to the design and putting together the electrical circuits, calibrating the sensors and the micro-controller.

After the fabrication of the model and the completion of the electrical circuits, we undertook the integration of the mechanical and electronic parts into one integrated unit for further testing. We tested the integrated unit on accuracy and robustness. If any changes or additions are required, we implement them and re-tested them until satisfactory results are obtained.

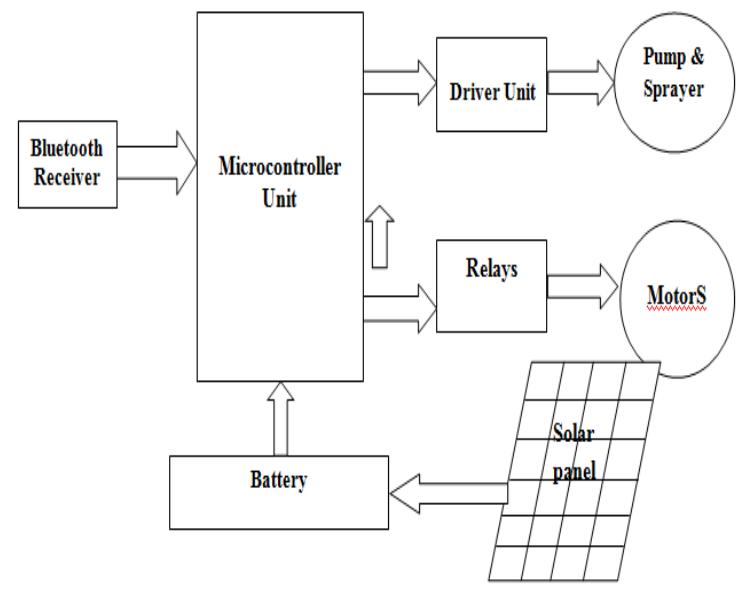

Fig. 7 Block diagram

The fig. 7 shown above is a block representation of the actual circuitry; the working is as given below: -

A $12 \mathrm{~V}$ battery powers the entire unit including the D.C. motors, pump, relays, Bluetooth device, microcontroller and Keil Software is used. As soon as the switch of the control unit is ON the vehicle starts moving and started spraying. Pairing has to be made between Android mobile and Bluetooth module. When we pressed the control switch in android app then it sends signal $\mathrm{F}$ indicating forward direction to Bluetooth receiver. The Bluetooth receiver receives a command to move forward, for that case the relays which were kept initially in closed position get switched and the relay controlling the right motor goes to open condition, thus shutting off the right motor. Thus facilitating a forward motion. To make a right turn or left turn, signal $\mathrm{R}$ or $\mathrm{L}$ is send to the micro-controller unit and vehicle then receives the signal and in this case the relay controlling the left motor goes to open and thus shutting off the left motor. Pump gets directly connected to battery via switch, pump needs to be switched to ON/OFF manually. This entire loop continues until the entire test-area has been sprayed with insecticide and then pump is switched off.

\section{APPLICATION}

- The solar sprayer is mainly used for spraying liquefied insecticides, bio-fertilizers.

- The energy resource is mainly a non-exhaustible type of Energy Resource.

- The developed system can be also used for spraying the fungicides as well.

- It can also be used as automatic Spray Painting robot.

- The same technique and technology can also be extended for all types of power sprayers.

- The pesticide sprayer operates with minimal pollution as the spraying is done very much uniformly with less wastage.

- This model can be also used as mosquito repellent.

\section{ADVANTAGES}

- The model so designed and tested will reduce fuel consumptions and brings down running cost due to Solar Powered Working.

- The sprayer not only minimizes the hard manual work but is also more effective and efficient than the conventional ones.

- The realized model prevents the operator from exposing to poisonous chemicals and pesticides.

- It is good alternative for engine sprayer.

- The use will be most welcomed when the fuel resources are over.

- It is noiseless and does not create any pollution.

- There is no vibration comparing with petrol or diesel operated sprayers.

- The construction is simple and exploited the use of latest technology and so not difficult as other sprayers.

- It is simple to use and easy to produce and manufacture in large numbers in quick time.

- The model is possessing good and long durability and exhibits good reliability. 


\section{CONCLUSION}

The work that is proposed is having the most convenience and the technology is playing a vital role to perform the common routine works in a more efficient effective way thereby the agronomics will be more profitable one along with health care taken about the labors who are working in the farmland and also a great way keeps animals also not exposed to fatal chemicals and there are every chances that the same can be further improved by using even wireless technologies that can be even controlled through long distance monitoring of this work

\section{REFERENCES}

[1] Abhishek Jivrag, Vinayak Chawre, Aditya Bhagwat, Solar Operated Multiple Granulated Pesticide Duster, WCE 2011, July 6 - 8, 2011, London, U.K, Vol. III. ISBN: 978-988-192515-2.

[2] R. Joshua, V. Vasu and P. Vincent. (2010) "Solar Sprayer - An Agriculture Implement", "International Journal of Sustainable Agriculture” 2 (1): pp. 16-19, ISSN 20792107.

[3] Sagar P. Yadav, Pooja M. Kakad, Anushree V. Bhujade, "Solar Powered Sprayer For Agricultural Uses",

[4] M.Venkateswarlu, Dr. M.Ashok Kumar, "Agricultral Solar Sprayer With Multi Applications", IJRD, Vol.2, Issue. 4, pp 1-7.

[5] Abhilash Gurjar, Riyaz Mansuri, "Solar Powered Sprayer", IJFEAT, ISSN:23218134, 2015.

[6] B. van Campen, D. Guidi and G. Best, "Solar photovoltaics for sustainable agriculture and rural development", "Environment and Natural Resources" No. 2 FAO, Rome, 2000.

[7] International code of conduct on the distribution and use of pesticides by Food and Agricultural Organization of the United Nations Rome 2001

[8] http://www.nkkhoo.com/2013/03/23/a

[9] http://agricoop.nic.in/dacdivision/machinery1/ chap4.pdf

[10] http://nif.org.in/innovation/motorcycle_spraye r/244

[11] http://nif.org.in/innovation/bicycle_mounted_ sprayer/22. 